\title{
Modelling salt accumulation in an oval irrigated with recycled water
}

\author{
M.M. Rahman a , D. Hagare a, B. Maheshwari ${ }^{\text {b }}$, P. Dillon ${ }^{\mathrm{c}}$ \\ School of Computing, Engineering and Mathematics, University of Western Sydney, \\ Locked Bag 1797, Penrith, NSW 1797, Australia \\ School of Science and Health, University of Western Sydney, Locked Bag 1797, Penrith, \\ NSW 2751, Australia
}

CSIRO Land and Water, PMB2 Glen Osmond, SA 5064, Australia

Email: muhit.rahman@uws.edu.au

\begin{abstract}
Recycling of wastewater is important for achieving sustainable use of water in both urban and rural areas. Currently, in Australia, there are strict regulations on disposal and reuse of wastewater. Irrigation of sporting fields is one of the most common applications of wastewater recycling. However, there is an increased risk of soil salinity in the vadose zone when recycled water is used for irrigation. This is due to the generally increased levels of salt in the recycled water compared to that of town water supply. This paper presents salt transport modelling for a sporting oval (Greygums Oval) in Western Sydney which has been irrigated with recycled water for more than four years. The modelling was carried out for 1277 days using HYDRUS 1D, which is a one dimensional salt transport model. Meteorological data was used to specify atmospheric boundary conditions, which was collected from nearest weather station of Penrith Lakes, $4 \mathrm{~km}$ from the Greygums Oval. Average total dissolved solids (TDS) of recycled water varied in the range of $480-630 \mathrm{mg} / \mathrm{L}$. Hydraulic loading rate and salt loading of applied irrigation water were $160 \mathrm{~mm} /$ year and $713 \mathrm{~kg} / \mathrm{ha} /$ year, respectively.

The results of salt transport modelling of recycled water for irrigation showed a 77\% increase (from $0.38 \mathrm{~g} / \mathrm{L}$ to $0.67 \mathrm{~g} / \mathrm{L}$ ) in the root zone soil water TDS concentration over the period of 1277 days. However, during the simulation period, predicted TDS concentration showed significant fluctuations, which can be attributed to the influence of rainfall on soil water content and the movement of salt within the rootzone. The increasing trend was supported by a limited number of field data points. The field data collected generally supported the findings of the model. However, more field data are required to validate the model.

The results also indicate that weather conditions, particularly rainfall, appear to have significant impact on the accumulation of salt in the soil. That is, accumulation of salt in the soil due to recycled water applications can be more critical in the arid than in the tropical rainforest climatic conditions. For arid regions, due to limited availability of water, there is an increased pressure for using recycled water for irrigation. The results of this study appear to indicate that, if the recycled water is applied indiscriminately, the soils in this region may be under severe risk of salinization. However, further studies are required to quantify the risk of salinisation.
\end{abstract}

Keywords: Salt transport modelling, Urban irrigation, Vadose zone 


\section{INTRODUCTION}

Recycled water is the treated wastewater after removing solids and certain impurities. Characteristics of recycled water depend on its source, treatment level and geographic location. Recycled water characteristics can be classified according to its physical, chemical and biological aspects. Despite significant benefits of recycled water, there are several concerns related to environmental and health risks. One such concern relates to the increase of salinity including sodicity and bicarbonate hazards in irrigated fields. Salinity is the concentration of soluble salts in water that are measured as total dissolved solids or electrical conductivity (EC) of soil solution. As water evaporates from soils or is used by the plants, salts are left behind. This phenomenon increases the concentration of salts in the soil with time. This increase in salt concentration in the soil can adversely influence the amount of water a plant can take up from the soil due to the osmotic effect it creates. Several studies have reported increased salinity due to the prolonged use of recycled water for irrigation. Distinct long-term effects of recycled water use in terms of salinity have been observed in agricultural field by Dikinya \& Areola (2010). After three years of irrigation with recycled water, the electrical conductivity (EC) in soil increased from 105 to $235 \mu \mathrm{s} / \mathrm{cm}$ and $\mathrm{Na}^{+}$concentration increased from 2.95 to $5.75 \mathrm{meq} / 100 \mathrm{~g}$ of soil. Jahantigh (2008) reported $95 \%$ increase of salinity levels for a field which used recycled water for irrigation over five years. Increase of salinity in terms of $\mathrm{EC}, \mathrm{Na}^{+}$and $\mathrm{Cl}^{-}$are also reported in a number of other studies (Xu et al., 2010; Yang et al., 2006; Heidarpour et al., 2007; Gloaguen et al., 2007; Leal et al., 2009; Alarcón and Pedrero, 2009; Wang et al., 2003; Klay et al., 2010 and Adrover et al., 2012).

In the case of public open space including sporting oval irrigation, Candela et al. (2007) investigated the effect of recycled water irrigation in a golf course in Spain for two years. They observed that $\mathrm{Na}^{+}$increased in the top $0.6 \mathrm{~m}$ of soil profile due to water application and evapotranspiration. After four years of investigation of nine golf courses in Southern Nevada, which were irrigated using recycled water, Devitt et al. (2007) reported that the soil salinity levels followed a sinusoidal seasonal curve, where $70 \%$ of all the peaks occurred in summer. This indicated that the type of season has an effect on the salinisation to some extent.

Salt transport modelling is an efficient way to quantify salinity risk in irrigated fields (Ragab 2002, Bachceci and Suat 2007). The salinity issue can be understood by modelling the interaction among the soil, water and salt within the vadose zone. The main objective of the present study is to develop a methodology to predict soil salinity levels of a sporting oval that is irrigated with recycled water for a number of years. The modelling was carried out using HYDRUS 1D, which is a one dimensional salt transport model, to predict the soil salinity levels.

\section{STUDY AREA}

The Greygums oval $\left(33^{0} 43.652^{\prime} \mathrm{S}, \quad 150^{\circ}\right.$ $\left.42.406^{\prime} \mathrm{E}\right)$, is situated in Cranebrook, NSW, Australia (Figure 1). The oval is used for athletics during summer season and Australian Rules football during the winter season. This oval is irrigated by sprinkler method using the recycled water from the Penrith Sewage Treatment Plant (STP) since January 2008. The recycled water used for irrigation is stored in a 25,000 L concrete tank and up to $553 \mathrm{~kL} /$ day of recycled water is used for irrigation of the oval. Average TDS of recycled water varied in the range of 480-630 $\mathrm{mg} / \mathrm{L}$. Hydraulic loading rate and salt loading of applied irrigation water was $160 \mathrm{~mm} /$ year and 713 $\mathrm{kg} / \mathrm{ha} /$ year, respectively. Mean annual rainfall in the study area is $715.9 \mathrm{~mm}$, where wettest months are from October through to March and driest from April to September.

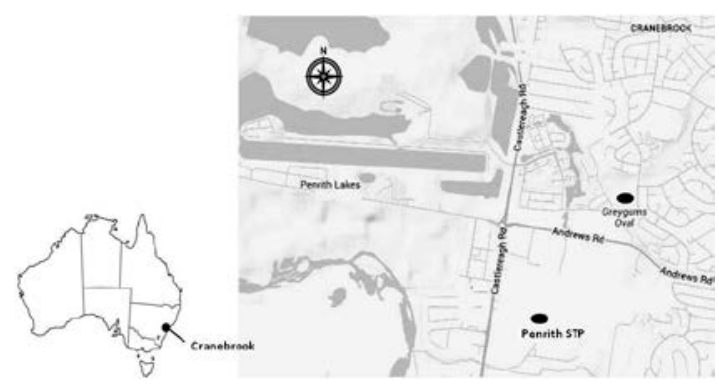

Figure 1. Map showing locations of Greygums oval and Penrith Sewage Treatment Plant (STP).

\section{HYDRUS-1D SIMULATION MODEL}

Hydrus 1D (Simunek et al., 2009) simulates one dimensional water flow and solute transport in incompressible, porous, variably saturated media. The model can be used for different regimes but in this study transient system is used. For water flow modelling Hydrus 1D uses Richards' equation (Celia et al., 1990; Xu and Shao, 2002): 
$\frac{\partial \theta}{\partial t}-\frac{\partial}{\partial z}\left(K_{z z} \frac{\partial h}{\partial z}\right)-\frac{\partial K_{z z}}{\partial z}-S=0$

Where, $K_{z z}=$ saturated hydraulic conductivity $\left[\mathrm{LT}^{-1}\right], \theta=$ volumetric moisture content $\left[\mathrm{L}^{3} \mathrm{~L}^{-3}\right], h=$ pressure head [L], $z=$ depth in the vertical direction (positive upward) [L], $t=$ Time [T], $S=$ sink term representing water uptake by plant roots $\left[\mathrm{L}^{3} \mathrm{~L}^{-3} \mathrm{~T}^{-1}\right]$.

For Hydraulic properties, Van Genuchten's equation (1980) was used, which provides relationships between the volumetric moisture content, effective saturation, hydraulic conductivity and specific moisture storage:

$\theta(h)= \begin{cases}\theta_{r}+\frac{\theta_{s}-\theta_{r}}{\left(1+(a|h|)^{p}\right)^{m}} & h<0 \\ \theta_{s} & h \geq 0\end{cases}$
$K(h)= \begin{cases}\mathrm{K}_{\mathrm{s}} \mathrm{S}_{\mathrm{e}}^{l}\left[1-\left(1-\mathrm{S}_{\mathrm{e}}^{1 / m}\right)^{\mathrm{m}}\right]^{2} & h<0 \\ K_{S} & h \geq 0\end{cases}$

Where, $m=1-(1 / n), n>1$

$S_{e}=\frac{\theta-\theta_{r}}{\theta_{s}-\theta_{r}}$

Where,

$S_{e}$ is effective saturation [Unitless], $a$ is the soil water retention function $\left[\mathrm{L}^{-1}\right], m$ and $n$ are empirical parameters [unitless], $\theta_{r}$ is residual moisture content $\left[\mathrm{L}^{3} \mathrm{~L}^{-3}\right], \theta_{s}$ is saturated moisture content $\left[\mathrm{L}^{3} \mathrm{~L}^{-3}\right], l$ is pore connectivity parameter. The value of $l$ in the hydraulic conductivity function was estimated to be about 0.5 as an average for general soil (Simunek et al., 2009).

For solute transport, it was assumed that the solutes were non-reactive and there was no solubilization or dissolution of soil minerals. The assumption permitted the salinity in soil to be modeled based on the convection-dispersion equation for nonreactive solution (Roberts et al., 2009). The partial differential equation governing one dimensional advective-dispersive transport for transient flow in a variable saturated soil can be written as (Xu and Shao, 2002; Simunek et al., 2009; Bunsri et al., 2008):

$\theta R \frac{\partial c}{\partial t}-\frac{\partial}{\partial z}\left(\theta D_{z} \frac{\partial c}{\partial z}\right)+q_{z} \frac{\partial c}{\partial z}=0$

Where, $R=1+\frac{\rho_{b} K_{d}}{\theta}$

$\rho_{b}$ is bulk density $\left[\mathrm{ML}^{-3}\right], K_{d}$ is distribution coefficient $\left[\mathrm{L}^{3} \mathrm{M}^{-1}\right], c$ is concentration of chemical in liquid phase $\left[\mathrm{ML}^{-1}\right], q_{z}$ is the volumetric flux density $\left[\mathrm{LT}^{-1}\right], D_{z}$ is dispersion coefficient $\left[\mathrm{L}^{2} \mathrm{~T}^{-1}\right]$ that accounts for both diffusion and hydrodynamic dispersion. $D_{z}$ is calculated using Simunek et al. (2005):

$D_{z}=\alpha_{1} \frac{\left|q_{z}\right|}{\theta}+D_{d} \tau$

Where, $\alpha_{1}$ is longitudinal dispersivity [L], $D_{d}$ is the ionic or molecular diffusion coefficient in free water $\left[\mathrm{L}^{2} \mathrm{~T}^{-1}\right], \tau$ is a tortuosity factor. The tortuosity factor was evaluated by using Millington and Quirk equation (Millington and Quirk, 1961):

$\tau=\frac{\theta^{\frac{7}{3}}}{\theta_{S}^{2}}$

The plant solute uptake was assumed to be negligible in the present study. The governing water flow and solute transport equations were solved using upstream weighting finite element method (Simunek et al., 2009).

\subsection{Soil profile and initial conditions}

The salt transport modelling was carried out for a soil profile of $1 \mathrm{~m}$. The root zone was assumed as 0 to 0.4 $\mathrm{m}$. Initial soil water content was set to a uniform value of $0.2\left(\mathrm{~m}^{3} \mathrm{~m}^{-3}\right)$ throughout the soil profile. Initial 
solute concentration was calculated from electrical conductivity of soil water $\left(E C_{s w}\right)$, which was determined using the following relationship (Ayers and Westcot, 1985; Stevens et al., 2008):

$E C_{s w}=2 \times E C_{e}$

Where, $E C_{e}$ is the saturated paste electrical conductivity, whose value was taken from Maheshwari (2011) as $0.296 \mathrm{dS} / \mathrm{m}$.

Textural distribution of soil was carried out of samples collected from the oval and the texture was determined as sandy loam comprising of $74.6 \%$ sand, $9.5 \%$ silt and $15.9 \%$ clay. The bulk density of the soil from the study area varied from $763 \mathrm{~kg} / \mathrm{m}^{3}$ at depth $0-0.25 \mathrm{~m}$ to $1355 \mathrm{~kg} / \mathrm{m}^{3}$ at depth $0.25-0.35 \mathrm{~m}$. Bulk density of top soil $(0-0.25 \mathrm{~m})$ is less than the usual range of 1100 to $1600 \mathrm{~kg} / \mathrm{m}^{3}$ because recycled organics were mixed with the soil in this depth to increase its porosity.

\subsection{Time variable boundary conditions}

Atmospheric and free drainage conditions were defined as boundary condition at the surface and bottom of the soil profile, respectively. Free drainage condition at the bottom of soil profile is assumed to designate the soil profile as partially saturated. Atmospheric boundary conditions were specified using meteorological data. From these data, daily values of the reference evapotranspiration rate $\left(\mathrm{ET}_{0}\right)$ were calculated using PenmanMonteith method (Simunek et al., 2009). Daily values of $\mathrm{ET}_{0}$ were generated by HYDRUS 1D, which was in the range of 0.3-8.5 mm/day. Meteorological data were collected from nearest weather station of Penrith Lakes (station number 067113), $4 \mathrm{~km}$ from the Greygums Oval (Bureau of Meteorology, 2012). Annual rainfall during year 2008 was $867.2 \mathrm{~mm}$ which is around 20\% more of mean annual rainfall of $715.9 \mathrm{~mm}$ in the study area. Annual rainfall in the study area during year 2009, 2010 and 2011 were $537.6 \mathrm{~mm}, 722.8 \mathrm{~mm}$ and $704.6 \mathrm{~mm}$, respectively. Variation of rainfall, irrigation rate and $\mathrm{ET}_{0}$ over the study period is shown in Figure 2.

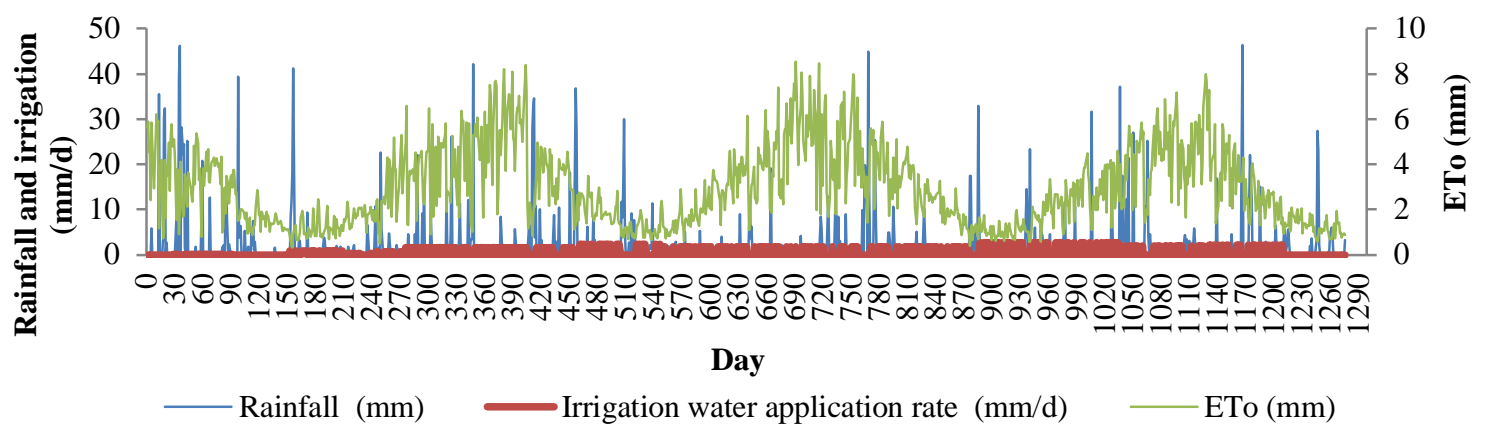

Figure 2. Variation of rainfall amount, $\mathrm{ET}_{0}$ and amount of irrigation water applied.

\subsection{Irrigation system and scheduling}

Greygums Oval has an above ground automatic watering system consisting of Rainbird Eagle E900 sprinkler heads. A submersible pump operates the irrigation system from a 22,000 L tank. Greygums oval was irrigated with recycled water since January 2008. The data related to monthly use of recycled water for irrigation were collected from Penrith City Council Grounds-man's logbook for the period between January 2008 and June 2011(Sheen, 2012). Using the monthly data appropriate application rates were calculated by taking into account the irrigation frequency. From January 2008 to February 2009 the irrigation frequency was three days per week but the irrigation scheduling was decreased to 2 days per week from March 2009 to June 2011. Figure 3 represents measured TDS value in irrigation water and the salt load applied during the irrigation.
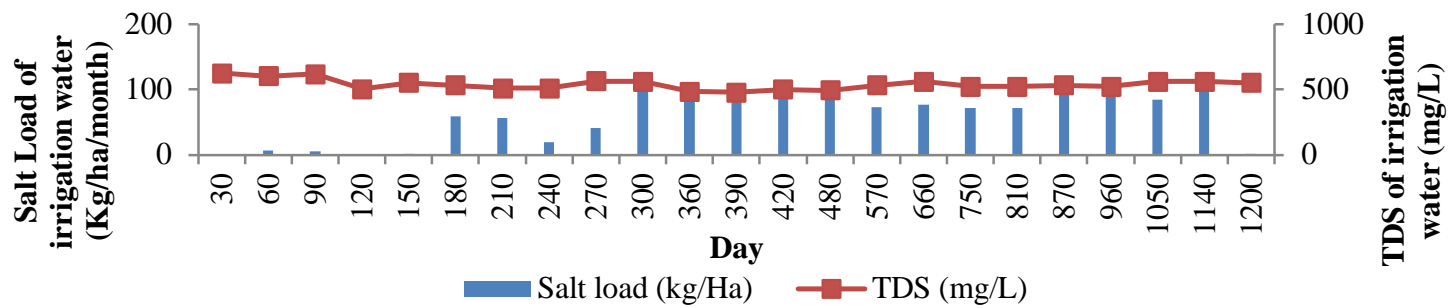

Figure 3. Variation of monthly salt load (indicated by columns) applied on the land and TDS concentration (indicated by the line) of recycled water used for irrigation. 


\section{RESULTS AND DISCUSSION}

\subsection{Soil hydraulic and solute transport parameters}

The hydraulic parameters including residual water content $\left(\theta_{\mathrm{r}}\right)$, saturated water content $\left(\theta_{\mathrm{s}}\right)$, shape parameters $\left(\alpha\right.$ and $n$ ) and saturated hydraulic conductivity $\left(\mathrm{K}_{\mathrm{s}}\right)$ were determined from the particle size distribution and bulk density of the soil with Rosetta model, which is implemented in HYDRUS 1D (Simunek et al., 2009) (Table 1). Dispersivity values at different depths were taken from Vanderborght and Vereecken (2007) and Kanzari et al. (2012). Root water uptake parameters were taken as equal to default values suggested in the built-in library of HYDRUS for turf grass.

Table 1. Soil hydraulic and solute transport parameters

\begin{tabular}{cccccccc}
\hline $\begin{array}{c}\text { Depth } \\
(\mathrm{m})\end{array}$ & $\begin{array}{c}\theta_{\mathrm{r}} \\
{[-]}\end{array}$ & $\begin{array}{c}\theta_{\mathrm{s}} \\
{[-]}\end{array}$ & $\begin{array}{c}\alpha \\
{[1 / \mathrm{cm}]}\end{array}$ & $\begin{array}{c}\mathrm{n} \\
{[-]}\end{array}$ & $\begin{array}{c}\mathrm{K}_{\mathrm{s}} \\
{[\mathrm{cm} / \mathrm{d}]}\end{array}$ & $\begin{array}{c}\text { l } \\
{[-]}\end{array}$ & $\begin{array}{c}\text { Dispersivity } \\
{\left[\mathrm{cm}^{-1}\right]}\end{array}$ \\
\hline $0-0.25$ & 0.0675 & 0.6244 & 0.0338 & 1.341 & 214.13 & 0.5 & 17.5 \\
$0.25-1.00$ & 0.0608 & 0.4418 & 0.0274 & 1.5327 & 86.59 & 0.5 & 5.5 \\
\hline
\end{tabular}

\subsection{Salt accumulation in soil over time}

The HYDRUS 1D simulation period for this study was set for 1277 days from January 2008 to June 2011. This period was selected mainly due to the availability of recycled water (RW) data. The average TDS concentration in the soil water in the root zone is shown in Figure 4 for the above period. As shown in this Figure, there appears to be significant fluctuations in the TDS concentration of the soil water over the study period. Root zone TDS concentration decreased during rainfall events, which can be due to the flushing of accumulated salt by the rain water towards the lower layers of the soil. Similar observations were reported by Ramos et al. (2011). However, there is generally an increasing trend in TDS concentrations. To demonstrate the impact of recycled water TDS concentration on salt accumulation in root zone, a scenario analysis was carried out for different irrigation water conditions as shown in Figure 4. As expected the soil water TDS concentration corresponding to irrigation with twice the recycled water TDS concentration (1.08 g/L) was found to be significantly higher than the concentrations obtained for the irrigation water with town water TDS concentration $(0.14 \mathrm{~g} / \mathrm{L})$. It is evident from this figure that using town water as irrigation water reduces the salt accumulation. In fact, as shown in Figure 4, use of town water for irrigation results in insignificant accumulation of salt in the root zone.

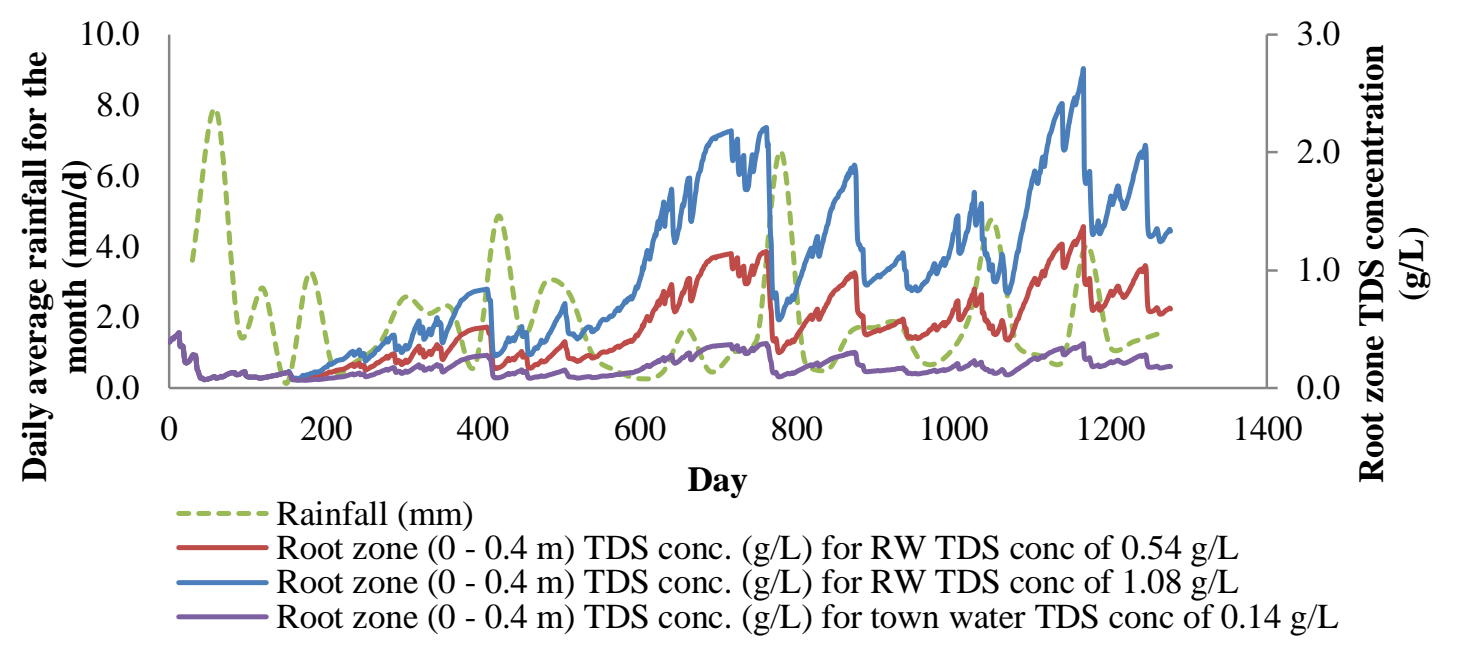

Figure 4. Variation of root zone TDS concentration.

The predicted TDS concentrations at depths 0 - $0.2 \mathrm{~m}$ and 0.7 - $1 \mathrm{~m}$ were compared with the measured TDS concentrations on two occasions (June 2008 and June 2010) as shown in Figure 5. The measured TDS concentrations at both the depths confirm increasing trend of the TDS in soil water over two years, which is in agreement with Figure 4. The TDS concentration measured in June 2008 at depth 0.7 - $1 \mathrm{~m}$ is close to the predicted value. Similarly, TDS measured in June 2010 at depth $0-0.2 \mathrm{~m}$ is close to the predicted value. Since only two observed data points for the soil salinity available, it is, at this stage, difficult to generalize the findings. More observed salinity data are required to conclusively establish the reliability of the model to 
predict the salt accumulation in sporting oval. Although the simulation predicts an increasing pattern of soil water TDS concentration at rootzone (Figure 4), yet the simulated TDS is not high enough to affect the growth of turfgrass (Kikuyu) existing in Greygums oval. According to NRMMC 2006, salt tolerance limit of Kikuyu is 1.8 to $3.6 \mathrm{~g} / \mathrm{L}$, which is well above the maximum simulated soil water TDS concentration of 1.37 g/L.

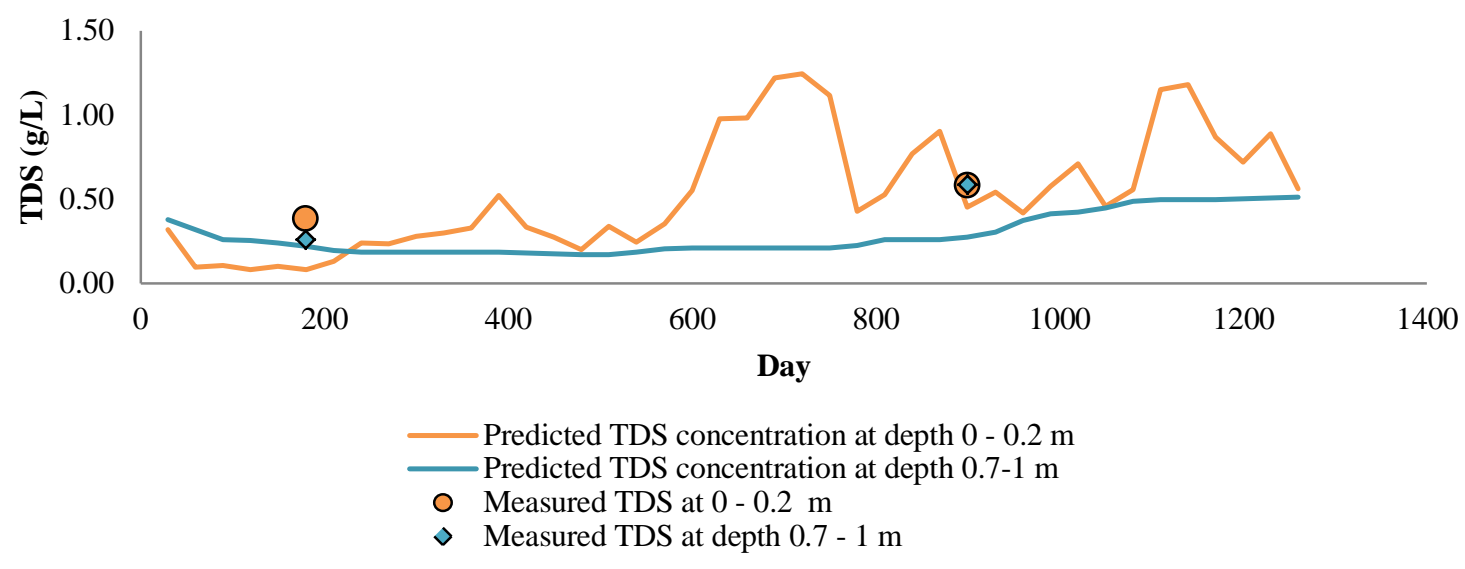

Figure 5. Observed and predicted TDS at different depth

\section{Conclusions}

The results of salt transport modelling of using recycled water for irrigation show $77 \%$ increase for root zone TDS concentration over 1277 days. However, during the simulation period, predicted TDS concentration showed significant fluctuations, which can be attributed to the influence of rainfall on soil water content and the movement of salt within the root zone. Scenario analysis showed that higher is the TDS concentration in the recycled water, higher is the accumulation in the soil root zone. For the period considered in this study, that is 1277 days (3.5 years), the simulated TDS concentration is below the salt tolerance limit of Kikuyu grass existing in Greygums oval. However, the trends in the current data indicate that the salt accumulation may reach or even exceed salt tolerance limits in the long run.

As evidenced by the results obtained, weather conditions, particularly rainfall, appears to have significant impact on the accumulation of salt in the soil. This means that the long-term accumulation of salt in the soil depends on, besides soil type, the rainfall and evaporation patterns. That is accumulation of salt in the soil due to recycled water applications can be more critical in the arid than in the tropical rainforest climatic conditions. For arid regions, due to limited availability of water, there is a pressure for using recycled water for irrigation. The results of this study appear to indicate that, if the recycled water is applied inappropriately, the soils in this region may be under severe risk of salinization. However, further studies are required to quantify the risk of salinisation.

\section{Acknowledgements}

The authors acknowledge the school of computing, engineering and mathematics, University of Western Sydney, for providing support for the research reported in this manuscript. The authors also wish to acknowledge Mr. Mal Sheen of Penrith city council for providing data related to Greygums oval irrigation. The lead author also acknowledges the support of CSIRO Water for a Healthy Country Program through a postgraduate research top-up award. The authors are grateful to the reviewers for their extremely useful comments.

\section{REFERENCES}

Adrover, M., Farrús, E., Moyà, G. \& Vadell, J. 2012. Chemical properties and biological activity in soils of mallorca following twenty years of treated wastewater irrigation. Journal of environmental management, 95, S188-S192.

Alarcón, J. \& Pedrero, F. 2009. Effects of treated wastewater irrigation on lemon trees. Desalination, 246, 631-639.

Ayers, R. S. \& Westcot, D. W. 1985. Water quality for agriculture, Food and Agriculture Organization of the United Nations Rome, Italy.

Bunsri, T., Sivakumar, M. \& Hagare, D. 2008. Numerical modeling of tracer transport in unsaturated porous media. Journal of Applied Fluid Mechanics, 1, 62-70. 
Rahman et al., Modelling of salt accumulation in an oval irrigated with recycled water

Bureau of Meteorology 2012. Climate data for station number 067113. Penrith.

Candela, L., Fabregat, S., Josa, A., Suriol, J., Vigues, N. \& Mas, J. 2007. Assessment of soil and groundwater impacts by treated urban wastewater reuse. A case study: Application in a golf course (girona, spain). Science of the total environment, 374, 26-35.

Celia, M. A., Bouloutas, E. T. \& Zarba, R. L. 1990. A general mass-conservative numerical solution for the unsaturated flow equation. Water resources research, 26, 1483-1496.

Devitt, D., Morris, M. \& Bird, R. 2007. Spatial and temporal distribution of salts on fairways and greens irrigated with reuse water. Agronomy Journal, 99, 692.

Dikinya, O. \& Areola, O. 2010. Comparative analysis of heavy metal concentration in secondary treated wastewater irrigated soils cultivated by different crops. International Journal of Environmental Science and Technology, 7, 337-346.

Gloaguen, T. V., Forti, M., Lucas, Y., Montes, C. R., Goncalves, R. a. B., Herpin, U. \& Melfi, A. J. 2007. Soil solution chemistry of a brazilian oxisol irrigated with treated sewage effluent. Agricultural Water Management, 88, 119-131.

Heidarpour, M., Mostafazadeh-Fard, B., Abedi Koupai, J. \& Malekian, R. 2007. The effects of treated wastewater on soil chemical properties using subsurface and surface irrigation methods. Agricultural Water Management, 90, 87-94.

Jahantigh, M. 2008. Impact of recycled wastewater irrigation on soil chemical properties in an arid region. Pakistan Journal of Biological Sciences, 11, 2264-2268.

Klay, S., Charef, A., Ayed, L., Houman, B. \& Rezgui, F. 2010. Effect of irrigation with treated wastewater on geochemical properties (saltiness, c, $\mathrm{n}$ and heavy metals) of isohumic soils (zaouit sousse perimeter, oriental tunisia). Desalination, 253, 180-187.

Leal, R. M. P., Herpin, U., Fonseca, A. F., Firme, L. P., Montes, C. R. \& Melfi, A. J. 2009. Sodicity and salinity in a brazilian oxisol cultivated with sugarcane irrigated with wastewater. Agricultural Water Management, 96, 307-316.

Maheshwari, B. 2011. Sustainability of sporting fields in western sydney-understanding issues and developing best practice management strategies, draft report.

Millington, R. \& Quirk, J. 1961. Permeability of porous solids. Transactions of the Faraday Society, 57, 1200-1207.

NRMMC 2006. Austrtalian guidelines for water recycling: Managing health and environmental risks (phase 1), 2006.

Roberts, T., Lazarovitch, N., Warrick, A. \& Thompson, T. 2009. Modeling salt accumulation with subsurface drip irrigation using hydrus-2d. Soil Science Society of America Journal, 73, 233-240.

Ramos, T.B., Simunek, J., Goncalves, M.C., Martins, J.C., Prazeres, A., Castanheira, N.L., Pereira, L.S. Field evaluation of a multicomponent solute transport model in soils irrigated with saline waters. Journal of Hydrology, 407 (2011) 129-144.

Sheen, M. 2012. RE: Reclaimed water management logbook for greygums oval

Simunek, J., Sejna, M., Saito, H., Sakai, M. \& Van Genuchten, M. T. 2009. The hydrus-1d software package for simulating the one-dimensional movement of water, heat, and multiple solutes in variablysaturated media. Manual for HYDRUS-1D software ed. University of California, Riverside.

Stevens, D. P., Smolenaars, S. \& Kelly, J. 2008. Irrigation of amenity horticulture with recycled water: A handbook for parks, gardens, lawns, landscapes, playing fields, golf courses and other public open spaces. Arris Pty Ltd, Melbourne.

Van Genuchten, M. T. 1980. A closed-form equation for predicting the hydraulic conductivity of unsaturated soils. Soil Science Society of America Journal, 44, 892-898.

Vanderborght, J. \& Vereecken, H. 2007. Review of dispersivity lengths for transport modeling in soils. Vadose Zone J, 6, 29-52.

Wang, Z., Chang, A., Wu, L. \& Crowley, D. 2003. Assessing the soil quality of long-term reclaimed wastewater-irrigated cropland. Geoderma, 114, 261-278.

Xu, J., Wu, L., Chang, A. C. \& Zhang, Y. 2010. Impact of long term reclaimed wastewater irrigation on agricultural soils: A preliminary assessment. Journal of hazardous materials, 183, 780-786.

Xu, P. \& Shao, Y. 2002. A salt-transport model within a land-surface scheme for studies of salinisation in irrigated areas. Environmental Modelling \& Software, 17, 39-49.

Yang, Y. L., Han, L. B., Zhang, Q. \& Su, D. R. 2006. Effects of reclaimed water irrigation on the physical and chemical characteristics of saline-alkaline earth in tianjin. Journal of Beijing Forestry University, 28, 85-91. 